\title{
COMPARATIVE EVALUATION OF FOUR DIFFERENT REMINERALIZING AGENTS ON DENTIN SURFACE TOPOGRAPHY: AN INVITRO STUDY
}

\author{
Mohamed Ahmed Wakwak* , Hamed Ibrahim Elkady* and Ibrahim Eldossoky Basha*
}

\begin{abstract}
This study was designed to evaluate the effect of four remineralizing agents on surface topography of dentin.

Materials and methods: 75 Teeth were divided according to the remineralizing agents into five treatment groups (Control C, CPP-ACP A, NovaMin V, n-HA N \& NaF F) 15 teeth each. Time of $\mathrm{pH}$ cycling periods were divided to (one week (W1), two weeks (W2) and five weeks (W5)

Results: Regarding all of $\mathrm{pH}$ cycle periods (W1, W2\&W5); there was statistically significant difference between mean dentinal tubules diameter values of the control group on one hand and each of A, V, N and F groups on the other hand. However, there was no statistically significance difference between all those remineralizing agents. The $\mathrm{N}$ groups showed the lowest mean value of dentinal tubules diameter while the F groups showed the highest mean value of dentinal tubules diameter.

Conclusions: Surface topography of dentin is positively affected by the application of remineralizing agents. Increasing the application rate ( $\mathrm{pH}$ cycling periods) of the remineralizing agents significantly affect the surface topography of dentin.
\end{abstract}

KEYWORDS Remineralizing agent, Surface topography, Nano-hydroxyapatite

\section{INTRODUCTION}

Dental caries is one the most offensive derangement of tooth structure ${ }^{(1)}$. Demineralization of enamel is the first sign of white spot lesion and progression of mineral loss and disintegration by acids lead to dentin involvement. Various agents with different forms to overcome the demineralization challenge $^{(2)}$.

One of the most effective demineralizing agents in caries prevention is fluoride. Nevertheless, some concerns have been expressed about fluorosis and total fluoride intake ${ }^{(3)}$. In recent years, fluoride

\footnotetext{
* Lecturer of Operative Dentistry, Faculty of Dental Medicine, Al Azhar University.
} 
alternative have been proposed, including CPPACP and nano-hydroxyapatite (NHA) because of their anticariogenic characteristics ${ }^{(4)}$. Calcium and phosphate crystals that are found in NHA as biocompatibility and low solubility in humid environments ${ }^{(5)}$. Enamel repair with NHA due to its chemical and structural similarity to tooth mineral content was reported in comparison to Sodium fluoride ${ }^{(5)}$.

Calcium and phosphate are essential components in the presence of CPP to remain soluble and biologically available on dentin surfaces ${ }^{(6)}$. The CPP-ACP-containing paste can also reduce dentin hypersensitivity successfully ${ }^{(7)}$. The possible mechanism by which CPP-ACP seals the exposed dentinal tubules may involve remineralization ${ }^{(8)}$. Under acidic conditions, CPP-ACP can extract calcium phosphate, CPP-ACP can also increase and maintain high concentrations of calcium and phosphate ions on dentin surfaces, thereby impeding demineralization and promoting remineralization ${ }^{(9)}$.

The efficacy of NovaMin-containing toothpaste in relieving hypersensitivity through physical occlusion of exposed dentin tubules has been long demonstrated ${ }^{(10)}$. The mode of action of this material is based on its chemical reactivity with aqueous solutions. When introduced into the oral environment, the material reportedly releases sodium, calcium and phosphate which then interact with the oral fluids and result in the formation of a crystalline hydroxycarbonate apatite layer that is structurally and chemically similar to natural tooth mineral (11). However, the calcium and phosphate ions are protected by glass and the glass particles need to be trapped for the calcium and phosphate to be localized, and this may cause a delay in the action of NovaMin ${ }^{(12)}$. This condition could probably explain why NovaMin-containing paste applied on demineralized dentine can form a homogeneous layer covering the dentine surface with crystal-like deposits and tight combination with tubular walls ${ }^{(13)}$.
Also, Calcium sodium phosphosilicate glass particles occlude dentinal tubules physically and partially through the development of a crystalline hydroxyl-carbonate apatite layer. Moreover, it has been proposed that, the chemical reactions that promote apatite formation may also be useful at enhancement of remineralization and/or prevention of demineralization of early carious lesions ${ }^{(14)}$.

From the previous review of apatite formation that may enhance remineralization or prevention of demineralization on dentine. In this study, four types of remineralization agents seem likely to use for evaluating the effect of remineralizing topography of dentin and would be effective in conservative dentistry.

\section{MATERIAL AND METHODS}

A total number of 75 sound non carious human molars were used in this study. Teeth were stored in distilled water at room temperature until use. The teeth were divided into five treatment groups (Control C, CPP-ACP A, NovaMin V, $n-H A \mathrm{~N} \&$ $N a F$ F) (table 1) 15 teeth each. Each group was further divided into three equal subgroups according to the $\mathrm{pH}$ cycling periods (one week (W1), two weeks (W2) and five weeks (W5) with 5 teeth for each.

Water-cooled Isomet low speed was used to wet grind the occlusal surfaces of these teeth until dentino-enamel junction. The teeth were sectioned at dimensions $(5 \times 3 \times 2 \mathrm{~mm})$ length, width and depth respectively resulting in dentinal block of $(3 \times 5 \mathrm{~mm}$ dimension \& $2 \mathrm{~mm}$ thickness). After preparation of the specimens, the occlusal surface of each dentine disc was sandblasted with 600-grit silicon carbide paper for $30 \mathrm{~s}$ to create a standard flat dentin surface. Each specimen was evaluated for any microcracks using magnifying lens, and then was stored under in distilled water in closed, labeled containers.

Dentin demineralization was prepared by immersion in the demineralized solution $(2.2 \mathrm{mM}$ 
TABLE (1): Materials used in the study:

\begin{tabular}{|c|c|c|c|}
\hline & Brand name & Composition & Manufacturer \& website \\
\hline 1 & $\begin{array}{l}\text { GC Tooth } \\
\text { Mousse }\end{array}$ & $\begin{array}{l}\text { Pure water, glycerol, } \mathrm{CPP}-\mathrm{ACP}^{0 *}, \mathrm{~d} \text {-sorbitol, Xylitol, } \mathrm{CMC}-\mathrm{Na} \text {, } \\
\text { propylene glycol, } \mathrm{H} 2 \mathrm{O}, \mathrm{SiO} 2, \mathrm{TiO} 2, \mathrm{ZnO} 2, \mathrm{H} 3 \mathrm{PO} 4, \mathrm{MgO} 2, \\
\text { Guar gum, sodium saccharin, ethyl } p \text {-hydroxybenzoate, butyl } \\
\text { p-hydroxybenzoate and propyl } p \text {-hydroxybenzoate. }\end{array}$ & $\begin{array}{l}\text { GC International, } \\
\text { Itabashi- Ku, } \\
\text { Tokyo, Japan. } \\
\text { www.recaldent.com }\end{array}$ \\
\hline 2 & $\begin{array}{l}\text { Sensodyne repair \& } \\
\text { protect }\end{array}$ & $\begin{array}{l}\text { Calcium Sodium Phosphosilicate (NovaMin), Sodium } \\
\text { Monofluorophosphate (1450ppm Fluoride), PEG-8, Silica, } \\
\text { Glycerin, Sodium Methyl Cocoyl Taurate,Aroma, Sodium } \\
\text { Saccharin, Carbomer, Titanium Dioxide, Limonene, Linalool, } \\
\text { Cocamidopropyl Betaine }\end{array}$ & $\begin{array}{l}\text { Smithkline Beecham } \\
\text { limited,UK. } \\
\text { www.sensodyne.com }\end{array}$ \\
\hline 3 & Biorepair plus & $\begin{array}{l}\text { Aqua, Zinc Hydroxyapatite, Glycerin, Sorbitol, Cellulose } \\
\text { Gum, PEG-32, Silica, Sodium Myristoyl Sarcosinate, Sodium } \\
\text { Methyl Cocoyl Taurate, Aroma,Sodium Saccharin, Citric } \\
\text { Acid, Phenoxyethanol, Benzyl Alcohol, Sodium Benzoate. }\end{array}$ & $\begin{array}{l}\text { Bielefeld, Germany } \\
\text { www.biorepair.co.uk }\end{array}$ \\
\hline 4 & Topex Neutral pH & $\begin{array}{l}\text { Sodium Fluoride (0.9/. fluoride ion from 2/. Sodium fluoride) } \\
\text { Purified Water, Carbopol } 974 \text { Pnf/ Carbomer Homopolymer } \\
\text { Type B, Xanitham Gum, Disodium Phosphate, Anhydrous, } \\
\text { Sodium Hydroxide, Artificial Strawberry Flavor, Benzoic } \\
\text { Acid, Sodium Saccharin, Methyl Paraben. }\end{array}$ & $\begin{array}{l}\text { Sultan Healthcare, } \\
\text { USA } \\
\underline{\text { www.sultanhc.com }}\end{array}$ \\
\hline
\end{tabular}

$\mathrm{CaCl}_{2}, 2.2 \mathrm{mM} \mathrm{KH}_{2} \mathrm{PO}_{4}, 0.05 \mathrm{M}$ acetic acid the $\mathrm{pH}$ adjusted to 5 with $1 \mathrm{M} \mathrm{KOH}$ ) at $\mathrm{pH} 5.0$ at $37^{\circ} \mathrm{C}$ for 3 days. The solution was changed on daily basis and were not stirred or replaced during the demineralization period. The $\mathrm{pH}$ values of the demineralizing solutions was monitored daily by $\mathrm{pH}$ meter, ( $\mathrm{pH}$ electrode GE 100 BNC connected to $\mathrm{pH}$-meter GMH 3510;), and slight elevations were corrected with small amounts of hydrochloric acid $(\mathrm{HCl})$ to maintain a constant $\mathrm{pH}$ value 4.99 and 5.01 for dentine during the demineralization period. Standard buffer solution $(1.5 \mathrm{mM}(\mathrm{CaCl} 2), 0.9 \mathrm{mM}(\mathrm{NaH}-$ 2PO4), $0.15 \mathrm{M}(\mathrm{KCl})$ an the $\mathrm{pH}$ was adjusted using $5 \mathrm{M}(\mathrm{KOH})$ to $7.0 \mathrm{pH}$ ) with nominal $\mathrm{pH}$ values of 4.0 and 7.0, respectively, and with an accuracy of 0.01 units were used to calibrate the $\mathrm{pH}$ meter. Subsequently, the dentin samples were washed using deionized water to remove any excess acids.

Teeth specimens were subjected to $\mathrm{pH}$ cycling model. The daily cycle involved three hours of demineralization twice a day, with two hours of remineralization in between. After the daily cycle, the teeth specimens were placed in artificial saliva (0.4g NaCl, 0.4g KCl, 0,6g CaCl, $0.6 \mathrm{~g} \mathrm{NaH}_{2} \mathrm{PO}_{4}$, $4 \mathrm{~g}$ Urea, $4 \mathrm{~g}$ Mucin, $0.0016 \mathrm{~g} \mathrm{Na}_{2} \mathrm{~S}, 0.0016 \mathrm{~g}$ $\mathrm{Mg}_{2} \mathrm{P}_{2} \mathrm{O}_{7}+1 \mathrm{~L}$ distilled water at $\mathrm{pH}$ 7) overnight. The specimens received treatment three times daily; before the first demineralization and before and after the second demineralization, respectively at $37^{\circ} \mathrm{C}$.

All solutions were freshly prepared before each phase of the $\mathrm{pH}$ cycle and the $\mathrm{pH}$ values for the demineralizing and remineralizing solutions were checked prior to insertion of the specimens during each phase. During pH cycling, all specimens were placed in glass jar to ensure that they were fully immersed in the treatment solutions, to simulate the oral environment.

Environmental Scanning Electron Microscope (ESEM) assessment; 35 random selected specimens 
were subjected to surface analysis for assessment of surface topography of the samples by the Environmental Scanning Electron Microscope (ESEM) using ESEM Model Quanta 250 FEG (Field Emission Gun) with accelerating voltage $30 \mathrm{~K} . \mathrm{V}$., magnification14x up to 1000000 and resolution for Gun.1n.

Surface treatments; For each of the three main groups all specimens were immersed in demineralization agent for 3 days. Then treated with each respective remineralizing agent as follow: the occlusal dentinal surfaces were brushed with tooth mousse a $\mathrm{CPP}-\mathrm{ACP}$-containing paste for 3 minutes and undergo $\mathrm{pH}$ cycling, then immersed in artificial saliva. Consequently, the surfaces were brushed with Sensodyne paste containing NovaMin for 3 minutes with artificial saliva and $\mathrm{pH}$ cycling and then immersed in artificial saliva. While, the surfaces were brushed with Biorepair paste containing Nano hydroxyapatite for 3 minutes and $\mathrm{pH}$ cycling then immersed in artificial saliva. The surfaces were brushed with Topex Neutral pH containing sodium fluoride for 3 minutes and $\mathrm{pH}$ cycling then immersed in artificial saliva while group $C$ did not receive any remineralizing regimen, but undergo to $\mathrm{pH}$ cycling and storage in artificial saliva as a positive control subgroup. Artificial saliva was changed daily for five weeks in the previous protocol; prior each spectrum taken the specimen's surfaces was rinsed with distilled water.

The data were collected, tabulated and statistically analyzed by Kolmogorov-Smirnov and Shapiro-Wilk tests and showed parametric (normal) distribution. ANOVA test was used followed by Tukey's post-hoc were used to compare between different variables. The significance level was set at $\mathrm{P} \leq 0.05$. Statistical analysis was performed with IBM ${ }^{\circledR}$ SPSS $®$ Statistics Version 20 for Windows.

\section{RESULTS}

The mean and standard deviation values were calculated for each group in each assessment (ESEM, EDX)

\section{Effect of remineralizing agents on (COT\%):}

Regarding all of $\mathrm{pH}$ cycle periods (W1,W2\&W5); there was statistically significant difference between mean COT values of control group on one hand and each of $\mathrm{A}, \mathrm{V}, \mathrm{N}$ and $\mathrm{F}$ groups on the other hand. However, there was no statistically significance difference between all those remineralizing agents. The $\mathrm{N}$ groups showed the highest mean value of COT while the $\mathrm{F}$ groups showed the lowest mean value of COT.

\section{Effect of pH cycling periods on (COT\%):}

Regarding the control, A, V, N and F groups the mean COT\% values after five weeks (W5) revealed statistically significantly highest value followed by two weeks (W2) and the lowest one was after one week (W1).

For Control (CS) groups, there was statistically significance difference between CSWI (1.66 \pm 0.57$)$,

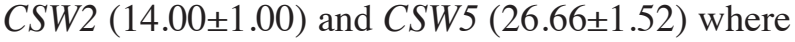
CSW5 showed the highest mean of COT\% while CSW1 showed the lowest mean of COT\%.

For CPP-ACP $(A S)$ groups, there was statistically

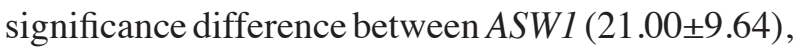
$A S W 2(57.33 \pm 2.51)$ and ASW5 (79.00 \pm 3.60$)$ where ASW5 showed the highest mean of COT\% while $A S W 1$ showed the lowest mean of COT\%.

For NovaMin (VS) groups, there was statistically significance difference between VSWI (17.33 \pm 2.51$)$, VSW2 (56.33 \pm 7.09$)$ and VSW5 (77.66 \pm 2.51$)$ where VSW5 showed the highest mean of COT\% while VSW1 showed the lowest mean of COT \%. 
TABLE (2) The mean and standard deviation (SD) values of different remineralizing agents regarding $\mathrm{pH}$ cycling periods on (COT\%).

\begin{tabular}{|c|c|c|c|c|c|c|}
\hline pH cycling material & $\begin{array}{c}\text { Control }(C) \\
\text { Mean } \pm \text { SD }\end{array}$ & $\begin{array}{c}\text { CPP-ACP (A) } \\
\text { Mean } \pm \text { SD }\end{array}$ & $\begin{array}{c}\text { NovaMin }(\mathrm{V}) \\
\text { Mean } \pm \text { SD }\end{array}$ & $\begin{array}{c}\text { Nano-hydroxy } \\
\text { apatite }(\mathbf{N}) \\
\text { Mean } \pm \text { SD }\end{array}$ & $\begin{array}{l}\mathrm{NaF} \quad(\mathrm{F}) \\
\text { Mean } \pm \mathrm{SD}\end{array}$ & $P$-value \\
\hline Week1 (W1) & $1.66 \pm 0.57$ & $21.00 \pm 9.64$ & $17.33 \pm 2.51$ & $21.66 \pm 7.63$ & $16.00 \pm 1.00$ & $<0.05^{*}$ \\
\hline Week2 (W2) & $14.00 \pm 1.00$ & $57.33 \pm 2.51$ & $56.33 \pm 7.09$ & $65.00 \pm 5.00$ & $54.00 \pm 9.64$ & $<0.05^{*}$ \\
\hline Week5 (W5) & $26.66 \pm 1.52$ & $79.00 \pm 3.60$ & $77.66 \pm 2.51$ & $80.66 \pm 6.02$ & $76.66 \pm 7.63$ & $<0.05^{*}$ \\
\hline p-value & $<0.05^{*}$ & $<0.05^{*}$ & $<0.05^{*}$ & $<0.05^{*}$ & $<0.05^{*}$ & \\
\hline
\end{tabular}

*; significant $(p<0.05) \quad n s ;$ non-significant $(p>0.05)$

TABLE (3) The mean and standard deviation (SD) values of different $\mathrm{pH}$ cycling periods regarding remineralizing agents on (COT\%).

\begin{tabular}{|l|c|c|c|c|}
\hline pH cycling & $\begin{array}{c}\text { Week1 (W1) } \\
\text { Mean } \mathbf{f} \text { SD }\end{array}$ & $\begin{array}{c}\text { Week2 (W2) } \\
\text { Mean } \pm \text { SD }\end{array}$ & $\begin{array}{c}\text { Week5 (W5) } \\
\text { Mean } \pm \text { SD }\end{array}$ & $P$-value \\
\hline Control (C) & $1.66 \pm 0.57$ & $14.00 \pm 1.00$ & $26.66 \pm 1.52$ & $<0.05^{*}$ \\
\hline CPP-ACP (A) & $21.00 \pm 9.64$ & $57.33 \pm 2.51$ & $79.00 \pm 3.60$ & $<0.05^{*}$ \\
\hline NovaMin (V) & $17.33 \pm 2.51$ & $56.33 \pm 7.09$ & $77.66 \pm 2.51$ & $<0.05^{*}$ \\
\hline Nano-hydroxy apatite (N) & $21.66 \pm 7.63$ & $65.00 \pm 5.00$ & $80.66 \pm 6.02$ & $<0.05^{*}$ \\
\hline NaF (F) & $16.00 \pm 1.00$ & $54.00 \pm 9.64$ & $76.66 \pm 7.63$ & $<0.05^{*}$ \\
\hline$p$-value & $>0.05 \mathrm{~ns}$ & $>0.05 \mathrm{~ns}$ & $>0.05 \mathrm{~ns}$ & $<$ \\
\hline
\end{tabular}

*; significant $(p<0.05) \quad n s ;$ non-significant $(p>0.05)$

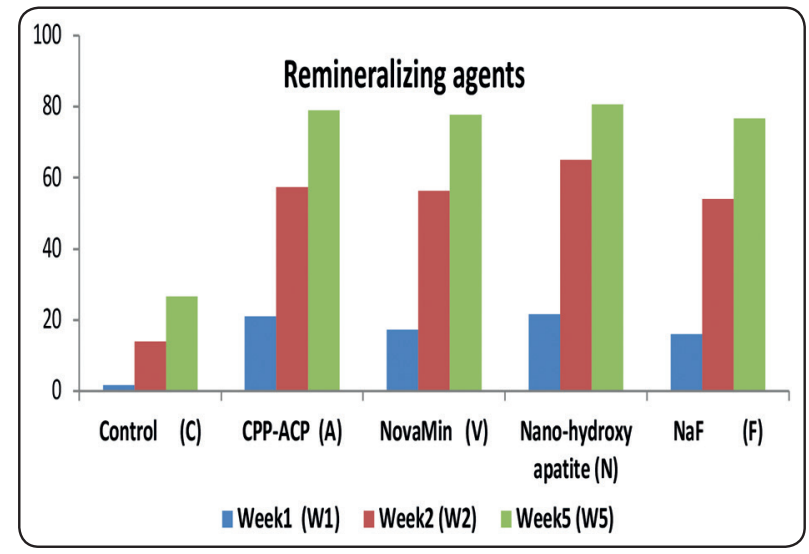

Fig. (1) Bar chart representing different remineralizing agents regarding $\mathrm{pH}$ cycling on $(\mathrm{COT} \%)$.

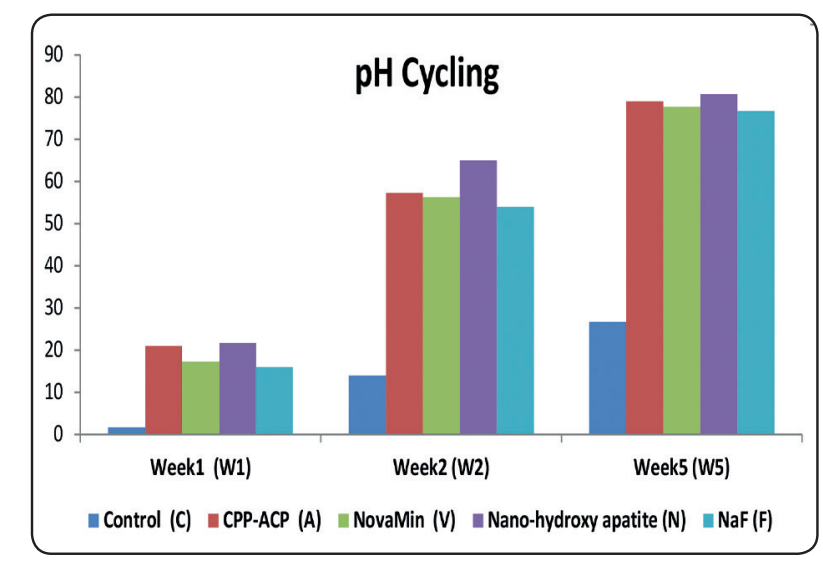

Fig. (2) Bar chart representing different $\mathrm{pH}$ cycling regarding remineralizing agents on (COT\%) 
For Nano-hydroxyapatite (NS) groups, there was statistically significance difference between NSW1 (21.66 \pm 7.63$), N S W 2(65.00 \pm 5.00)$ and NSW5 (80.66 \pm 6.02$)$ where NSW5 showed the highest mean of COT\% while NSWI showed the lowest mean of СOT\%.

\section{ESEM ASSESMENT}

Environmental scanning electron microscope (ESEM) investigation was revealed a nondestructive surface analysis of dentinal tubules It also provides three-dimensional topographical images of patent dentinal tubules and information of demineralization/remineralizing particles.

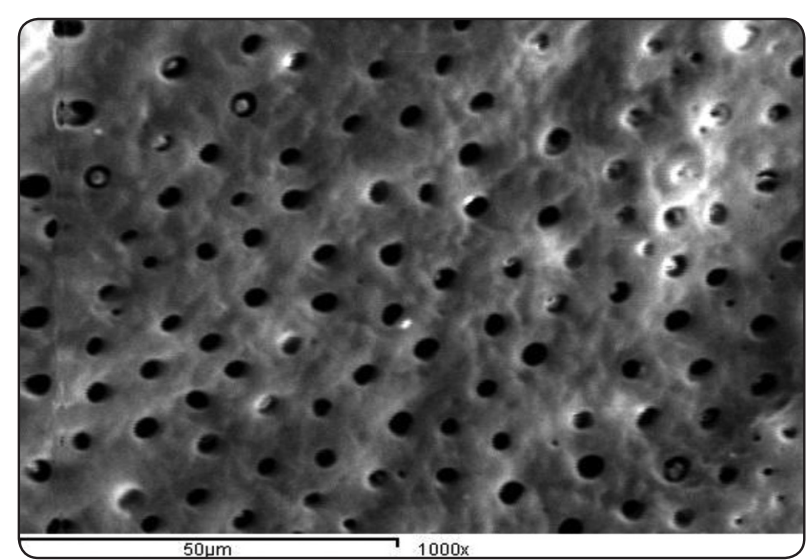

Fig. (3) Showing ESEM image of demineralized dentin at 1000x.

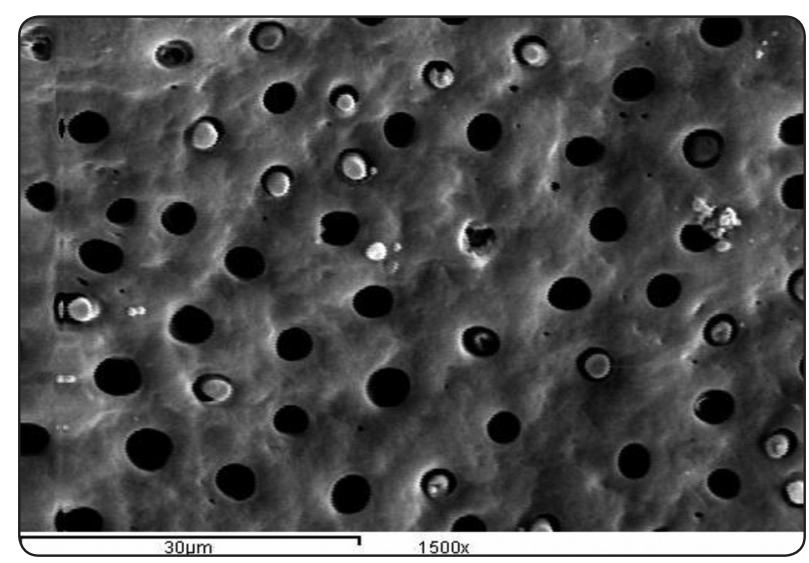

Fig. (4) Showing ESEM image of dentin treated with CPP-ACP at $1500 \mathrm{x}$

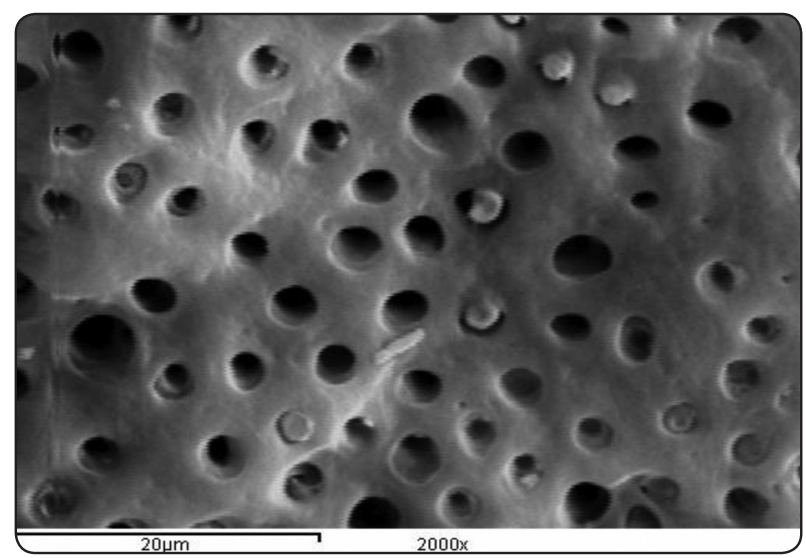

Fig. (5) Showing ESEM image of dentin treated with NovaMin at $2000 \mathrm{x}$

\section{DISCUSSION}

Environmental scanning electron microscope (ESEM) investigation was selected because it is a non-destructive approach for surface analysis. It also provides high-resolution, three-dimensional images and topographical information. ESEM has been used in many previous investigations for the effect of desensitizing toothpaste on dentin tubule diameter and occlusion ${ }^{(15)}$. ESEM was used in the study for qualitative assessment and ultramorphological examination for the treated surfaces of dentin ${ }^{(16)}$.

After dentin demineralization the ESEM images showed complete removal of smear layer and smear plug from dentinal tubules with patent uniform orifices, also wider and a larger number of dentinal tubules were found than sound dentin In This study the CPP-ACP (A), NovaMin (V), NHA (N) and NaF (F) groups showed precipitation and deposition of $\mathrm{Ca} \& \mathrm{PO} 4$ nano-particles with different thickness on dentin surface which have been recorded by the ESEM, with statistically significant decrease in diameter of dentinal tubules and significantly more tubule occlusion than the control group for $\mathrm{pH}$ cycle at one week (W1), two weeks (W2)\& five weeks (W5). This result agrees with that found by previous studies in which both toothpastes have showed similar extent of dentinal tubules occlusion ${ }^{(17)}$. 
The higher effect of NHA-containing toothpaste has been attributed to elevation of calcium concentrations, causing the remineralization of early caries lesions in an in-situ study ${ }^{(18)}$. NHA in dentifrice is reported to function by directly filling up micropores on demineralized tooth surfaces, and when it penetrates dentinal tubules it acts as a template in the remineralization process by continuously attracting large amounts of calcium and phosphate ions from the remineralization solution to the tooth tissue, thus promoting crystal integrity and growth ${ }^{(19)}$. Within the study period, the control group produced a relatively negligible amount of completely occluded tubules and precipitates layer deposit and caused no significant reduction in diameter of the dentin tubules or its occlusion in relative to the untreated tubules at base line ${ }^{(20)}$.

The results of this study is in agreement with Alafifi et al. ${ }^{(21)}$ who found that using Nano-hydroxyapatite has the ability to occlude the opened dentinal tubules because of the size of the nanoparticles which was smaller than the size of the dentinal tubules, it is possible that the carbonated apatite nanoparticles adhered to opened dentinal tubules. In addition, the nano-sized particles have an affinity and can induce deposition on irregular spaces (22). This was also confirmed by researches as $\mathbf{L e i} \boldsymbol{X}$ et al $^{(23)}$ who reported that Nano-hydroxyapatite is the most similar compound to the dental tissue having characteristics such as biological compatibility, remineralization potential, antimicrobial growth and nanoparticles size.

The result of this study demonstrated that CPPACP and NovaMin-containing toothpastes showed equal effectiveness in occluding dentin tubules as well as depositing precipitate layers over and within the dentin tubules, while fluoride toothpaste have little effect in remineralizing potentiality.

Calcium and phosphate are essential components of dentin in the form of highly insoluble complex (hydroxyapatite); in the presence of CPP, these minerals remain soluble and biologically available on dentin surfaces ${ }^{(24)}$. The CPP-ACP-containing paste can also reduce dentin hypersensitivity successfully. The possible mechanism by which CPP-ACP seals the exposed dentinal tubules may involve remineralization ${ }^{(25)}$. Under acidic conditions, CPPACP can extract calcium phosphate, CPP-ACP can also increase and maintain high concentrations of calcium and phosphate ions on dentin surfaces, thereby impeding demineralization and promoting remineralization ${ }^{(26)}$.

The results of this study revealed that a statistically significant difference was found between the one week, two weeks and five weeks (W1, W2\&W5) pH cycle period. Regardless of the applied surface treatment the $\mathrm{W} 5 \mathrm{pH}$ cycle provided the higher dentinal tubule occlusion and demonstrated that increased usage of the dentifrice was associated with decrease in dentinal tubules diameter and increase in completely occlusion tubules percentage (COT\%) and a concomitant decrease in partial occlusion tubules percentage (POT\%) and fully opened tubules percentage (FOT\%). This ability of the remineralizing agents, as demonstrated in the present study, for precipitative occlusion of dentin tubules and deposit a precipitate layer over and within the dentin tubules explained the relief of bleaching related tooth sensitivity by NHA toothpaste reported by Philip $\boldsymbol{N}^{(27)}$ in agreement with this study.

In the current study concerning the one-week pH cycle; some dentinal tubules were occluded superficially; a thin, membrane-like coating was formed on demineralized dentine surface. The presence of several patented tubules may be attributed to the short application time. The current study suggested that the recommended application time (3 min) of the manufacturer was short to induce enough remineralization of CPP-ACP by forming substances that occlude dentinal tubules but become more prominent by increasing the time (5 weeks).

This results agreed with that revealed by Freire IR et $\boldsymbol{a l}^{(28)}$ who studied the effect NHA as an 
desensitizing agent and found it was very effective in reducing dentin hypersensitivity in a very short period of time with limited number of application.

However, this disagrees with Farooq I et al. ${ }^{(29)}$ who found that CPP-ACP or NovaMin deposits and retained smear layer might be unstable and conclude that the acid resistance of calcium-containing desensitizing pastes might also be limited. Therefore, phosphoric acid in artificial saliva likely dissolves loose calcium and phosphate deposits in dentinal tubules until it encounters mineralized dentine matrix, thereby reopening the tubules ${ }^{(30)}$.

\section{CONCLUSIONS}

1. The remineralizing agents have an influential effect on dentin surface topography.

2. Increasing the application rate $(\mathrm{pH}$ cycling periods) of the remineralizing agents significantly affect the surface topography.

3. The compositions of remineralizing agents produce different effect on dentin surface.

Conflict of interest: no conflict of interst

\section{REFERENCES}

1. Ten Cate JM, Duijsters PP. Alternating demineralization and remineralization of artificial enamel lesions. Caries Res 1982;16:201-10.

2. Daneshpoor N, Pishevar L. Comparative evaluation of bioactive cements on biomimetic remineralization of dentin. J Clin Exp Dent. 2020;12(3):291-9.

3. Xiao Z, Que K, Wang H, et al. Rapid biomimetic remineralization of the demineralized enamel surface using nano-particles of amorphous calcium phosphate guided by chimaeric peptides. Dent Mater 2017;33(11):1217-1228.

4. Elgamily H, Safwat E, Soliman Z, Salama H, El-Sayed H, Anwar M. Antibacterial and remineralization efficacy of casein phosphopeptide, glycomacropeptide nanocomplex, and probiotics in experimental toothpastes: an in vitro comparative study. Eur J Dent 2019;13(3):391-398.

5. Cardoso CdeA, Lacerda B, Mangueira DF, et al. Mechanisms of action of fluoridated acidic liquid dentifrices against dental caries. Arch Oral Biol 2015;60(1):23-28.
6. Kraivaphan P, Amornchat C. Comparative clinical efficacy of three toothpastes in the control of supragingival calculus formation. Eur J Dent 2017;11(1):94-98.

7. Carrouel F, Viennot S, Ottolenghi L, Gaillard C, Bourgeois D. Nanoparticles as anti-microbial, anti-inflammatory, and remineralizing agents in oral care cosmetics: a review of the current situation. Nanomaterials (Basel) 2020; 10 (01) $1-32$.

8. Tomaz PLS, Sousa LA, Aguiar KF. et al. Effects of 1450ppm fluoride-containing toothpastes associated with boosters on the enamel remineralization and surface roughness after cariogenic challenge. Eur J Dent 2020; 14 (01) 161170

9. Vilhena FV, Polassi MR, Paloco EAC, Alonso RC, Guiraldo RD, D'Alpino PH. Effectiveness of toothpaste containing REFIX technology against dentin hypersensitivity: a randomized clinical study. J Contemp Dent Pract 2020; 21 (06) 609-614.

10. Manchery N, John J, Nagappan N, Subbiah GK, Premnath P. Remineralization potential of dentifrice containing nanohydroxyapatite on artificial carious lesions of enamel: A comparative in vitro study. Dent Res J 2019;16:310-7.

11. Wang Y, Mei L, Gong L, Li J, He S, Ji Y, et al. Remineralization of early enamel caries lesions using different bioactive elements containing toothpastes: An in vitro study. Technol Health Care 2016;24:701-11.

12. Guclu ZA, Alacam A, Coleman NJ. A 12-week assessment of the treatment of white spot lesions with CCP-ACP paste and/or fluoride varnish. Biomed Res Int 2016; 2016:8357621.

13. Lelli M, Putignano A, Marchetti M, Foltran I, Mangani F, Procaccini M, Roveri N, Orsini G. Remineralization and repair of enamel surface by biomimetic $\mathrm{Zn}$-carbonate hydroxyapatite containing toothpaste: a comparative in vivo study. Front Physiol. 2014;5:1-6.

14. Bossù $M$, Saccucci $M$, Salucci $A$, Di Giorgio G, Bruni E, Uccelletti D, Sarto MS, Familiari G, Relucenti M, Polimeni A. Enamel remineralization and repair results of Biomimetic Hydroxyapatite toothpaste on deciduous teeth: an effective option to fluoride toothpaste. J Nanobiotechnology. 2019 25;17(1):17-22.

15. Almohefer SA, Levon JA, Gregory RL, Eckert GJ, Lippert F. Caries lesion remineralization with fluoride toothpastes and chlorhexidine - effects of application timing and toothpaste surfactant. J Appl Oral Sci. 2018 11;26:204-9. 
16. Sadoon NY, Fathy SM, Osman MF. Effect of Using Biomimetic Analogs on Dentin Remineralization with Bioactive Cements. Braz Dent J. 2020 Jan-Feb;31(1):44-51.

17. Braga RR, Fronza BM. The use of bioactive particles and biomimetic analogues for increasing the longevity of resin-dentin interfaces: A literature review. Dent Mater J. 2020 31;39(1):62-68.

18. Choi Y, Sun W, Kim Y, Kim IR, Gong MK, Yoon SY, Bae MK, Park BS, Park SB, Kim YI. Effects of Zn-Doped Mesoporous Bioactive Glass Nanoparticles in Etch-andRinse Adhesive on the Microtensile Bond Strength. Nanomaterials (Basel). 2020 29;10(10):194-13.

19. Jia L, Tao S, Yang J, Liang K, Yu Z, Gao Y, Fan M, Zhang M, He L, Li J. Adhesion of Streptococcus mutans on remineralized enamel surface induced by poly (amido amine) dendrimers. Colloids Surf B Biointerfaces. 2021;197:1114-09.

20. Elkassas D, Arafa A. Remineralizing efficacy of different calcium-phosphate and fluoride based delivery vehicles on artificial caries like enamel lesions. J Dent. 2014 Apr;42(4):466-74.

21. Alafifi A, Yassen AA, Hassanein OE. Effectiveness of polyacrylic acid-bioactive glass air abrasion preconditioning with NovaMin remineralization on the microhardness of incipient enamel-like lesion. J Conserv Dent. 2019;22(6):548-553.

22. Krishnan V, Bhatia A, Varma H. Development, characterization and comparison of two strontium doped nano hydroxyapatite molecules for enamel repair/regeneration. Dent Mater. 2016;32(5):646-59.
23. Lei X, Gao J, Xing F, Zhang Y, Ma Y, Zhang G. Comparative evaluation of the physicochemical properties of nano-hydroxyapatite/collagen and natural bone ceramic/ collagen scaffolds and their osteogenesis-promoting effect on MC3T3-E1 cells. Regen Biomater. 2019;6(6):361-371.

24. Bordea IR, Candrea S, Alexescu GT, Bran S, Băciuţ M, Băciut, G,et al. Nano-hydroxyapatite use in dentistry: a systematic review. Drug Metab Rev. 2020;52(2):319-332.

25. Kunam D, Manimaran S, Sampath V, Sekar M. Evaluation of dentinal tubule occlusion and depth of penetration of nano-hydroxyapatite derived from chicken eggshell powder with and without addition of sodium fluoride: An in vitro study. J Conserv Dent 2016;19:239-44.

26. Farooq I, Bugshan A. The role of salivary contents and modern technologies in the remineralization of dental enamel: a narrative review. F1000Res. 2020;9:171-9.

27. Philip N. State of the Art Enamel Remineralization Systems: The Next Frontier in Caries Management. Caries Res. 2019;53(3):284-295.

28. Freire IR, Pessan JP, Amaral JG. Anticaries effect of lowfluoride dentifrices with phosphates in children: a randomized, controlled trial. J Dent. 2016;50:37-42.

29. Farooq I, Ali S, Siddiqui IA. Influence of Thymoquinone Exposure on the Micro-Hardness of Dental Enamel: An In Vitro Study. Eur J Dent. 2019;13(3):318-322.

30. Arifa MK, Ephraim R, Rajamani T. Recent Advances in Dental Hard Tissue Remineralization: A Review of Literature. Int J Clin Pediatr Dent. 2019;12(2):139-144. 